Original Article

\title{
Clinical outcome of anterior vs posterior approach for cervical spondylotic myelopathy
}

\author{
Mario Alberto Cahueque Lemus*, Andres Enrique Cobar Bustamante, \\ Alfredo Ortiz Muciño, Gustavo Caldera Hernandez \\ Instituto Mexicano del Seguro Social, UMAE Hospital de Especialidades Centro Médico Nacional de Occidente, Guadalajara, Jalisco, Mexico
}

A R T I C LE I N F O

\section{Article history:}

Received 4 November 2015

Received in revised form 25 January 2016

Accepted 6 March 2016

Available online 26 March 2016

\section{Keywords:}

Cervical myelopathy

Decompression

Clinical outcome

Anterior approach

Posterior approach

\begin{abstract}
A B S T R A C T
Objective: The aim is to demonstrate whether there is clinical difference between posterior vs anterior decompression in cervical spondylotic myelopathy.

Methods: Forty-two patient database was obtained from the Centro Medico Nacional de Occidente in Mexico, those who underwent surgical treatment for cervical myelopathy with a mean 1.4 year followup.

Results: Patients were divided; group A (45\%) anterior approach and group B (55\%) posterior approach, for mJOA, group A had a lower score compare with group B. While in the Nurick score group B got a higher score compare with group A.

Conclusions: Posterior decompression resulted in better functional outcomes $(p<0.05)$.

(c) 2016 Prof. PK Surendran Memorial Education Foundation. Published by Elsevier, a division of Reed Elsevier India, Pvt. Ltd. All rights reserved.
\end{abstract}

The term cervical spondylotic myelopathy (CSM) was published in 1952, Brain et al. discovered the neurological signs and symptoms associated to medullar lesions secondary to vascular compromise. ${ }^{1}$ CSM is caused by the chronic compression of neurological elements, which together with spinal canal stenosis by ossification of the posterior longitudinal ligament forms the 2 most frequent causes of CSM. Patients with progressive neurological deterioration have surgical treatment indication, 50-75\% will show neurological recovery in the first 6 months follow-up. ${ }^{2,3}$

The choice of treatment in CSM can be anterior, posterior or combined approaches. The decision to choose an approach will depend on important factors: the cause of neurological compression (anterior structures, posterior structures or both), the number of affected segments, sagittal cervical balance and the surgeons experience in the surgical approach. Traditionally the anterior compression pathologies, either by disc herniation or bone spur formation in the posterior wall of the vertebral body, have been managed by anterior approach with corpectomy and fusion or discoidectomy and fusion. When there are 2 or 3 segments affected the posterior approach is recommended with laminectomy or

\footnotetext{
* Corresponding author. Tel.: +52 13310704802 .

E-mail address: mariocahueque@gmail.com (M.A. Cahueque Lemus).
}

laminoplasty. Realizing anterior approach, when there are 2 or more segments affected, raises the risk of no-union, stress in adjacent segments, cervical degeneration is augmented and swallowing can be difficult. ${ }^{2,4}$

Regarding cervical sagittal balance, there is evidence that the anterior approach offers better results than the posterior approach. There are various scales available to measure neurological function in patients with SCM, of which the most relevant are the modified Japanese Orthopedic Association scale and Nurick's scale (Tables 1 and 2). These scales can be used to evaluate results in neurological function after a posterior and anterior cervical decompression, comparing them at 1.4-year follow-up (Table 3). ${ }^{2,4-6}$

\section{Materials and methods}

Between 2013 and 2014, 42 patient database was obtained from the spine surgery module in Centro Medico Nacional de Occidente in Guadalajara, Mexico, these patients underwent multilevel decompressive surgery for CSM with a mean 1.4 year follow-up. Patients were localized by home phone numbers and follow-up appointments. Latest patient imagery was not evaluated.

Nineteen patients underwent an anterior decompression with corpectomy followed by placement of an expandable titanium 
Table 1

Modified Japanese Orthopaedic Association (mJOA) Score.

\section{Motor dysfunction score of the upper extremities}

Inability to move hands

Inability to eat with a spoon but able to move hands

Inability to button shirt but able to eat with a spoon

Able to button shirt with great difficulty

Able to button shirt with slight difficulty

No dysfunction

Motor dysfunction score of the lower extremities

Complete loss of motor and sensory function

Sensory preservation without ability to move legs

Able to move legs but enable to walk

Able to walk on flat floor with a walking aid

Able to walk up and/or down stairs with hand rail

Moderate to significant lack of stability but able to walk up and/or down stairs without rail

Mild lack of stability but walk unaided with smooth reciprocation

No dysfunction

Sensation

Complete loss of hand sensation

Severe sensory loss or pain

Mild sensory loss

No sensory loss

Sphincter dysfunction

Inability to urinate voluntary

Marked difficulty with micturition

Mild to moderate difficulty with micturition

Normal micturition

Table 2

Nurick scale.

\begin{tabular}{ll}
\hline Grading & Nurick clinical scale \\
\hline Grade 0 & $\begin{array}{l}\text { Signs and symptoms of root involvement but without } \\
\text { evidence of spinal cord disease }\end{array}$ \\
Grade 1 & $\begin{array}{l}\text { Sings of spinal cord diseases but no difficulty walking } \\
\text { Grade 2 }\end{array}$ \\
Grade 3 & $\begin{array}{l}\text { exployment difficulty in walking which does not prevent full-time } \\
\text { prevents full-time employment and occupation } \\
\text { Able to walk only with someone else's help or with the aid } \\
\text { of a walker }\end{array}$ \\
Grade 5 & Chairbound or bedridden \\
\hline
\end{tabular}

Table 3

Distribution.

\begin{tabular}{|c|c|c|}
\hline Gender & No. (\#) & Age (years \%) \\
\hline Feminine & 16 & 74 \\
\hline Anterior approach & 7 & 73 \\
\hline Posterior approach & 9 & 75 \\
\hline Masculine & 26 & 76 \\
\hline Anterior approach & 10 & 74 \\
\hline Posterior approach & 16 & 75 \\
\hline History of & No. (\#) & $(\%)$ \\
\hline \multirow[t]{3}{*}{ DM } & 8 & 19 \\
\hline & 6 women & 37 \\
\hline & 2 male & 7 \\
\hline \multirow[t]{3}{*}{ BHP } & 5 & 11 \\
\hline & 4 male & 15 \\
\hline & 1 women & 6 \\
\hline
\end{tabular}

Patient distribution. DM, diabetes mellitus; BHP, blood higher pressure.

cage to reconstruct the anterior column adding anterior cervical plate, and 18 patients underwent a posterior decompression with laminectomy followed by posterior instrumentation with lateral mass screws and 5 patients with laminoplasty. For a more accurate comparison with the anterior group, patients, who underwent a laminectomy greater than 4 levels, were excluded from the posterior group.
Thus, 42 patients were included in the study: 19 in the anterior group and 23 in the posterior group. These patients suffered from degenerative cervical spinal canal stenosis, and underwent decompressive surgery of the cervical spine sometime between 2013 and 2014. The primary symptom in all patients was myelopathy (CSM). In total, there were 26 men (10 anterior group, 16 posterior group) and 16 women (9 anterior group, 7 posterior group) who underwent operations. The patients' ages at operation ranged from 64 to 84 years old, with a mean of 75 years. The posterior group ( $77 \pm 8.8$ years) was significantly older than the anterior group ( $69 \pm 8.1$ years; $p=0.01)$.

The reasons for using the anterior approach were spondylosis in 13 patients, ossification of the posterior longitudinal ligament in 5 , degenerative kyphosis in 1 . The reasons for using the posterior approach were spondylosis in 19 patients, and ossification of the posterior longitudinal ligament in 4 . All patients were refractory to conservative treatment. The decision to use the chosen procedure depended on 3 main factors: direction of spinal cord compression, preoperative cervical alignment and the number of affected levels. Radiological examinations included plain radiography, MR imaging, and CT scan. Stability was assessed in the anterior and posterior groups. Latest patient imagery was not evaluated.

The 19 patients in the anterior group were treated using a corpectomy followed by placement of an expandable titanium cage to reconstruct the anterior column and cervical plate was added in all. In the posterior group, a 2- to 4-level laminectomy followed by posterior instrumentation with lateral mass screws was performed in 18 cases and 5 with laminoplasty (open door with sutured to the espinous process to avoid closure). Follow-up was 1.4 years. Clinical outcome was assessed before and after surgery using the Nurick score and the mJOA scale score. The chisquare test, and $t$-test were used for statistical analysis of data. Results were considered significant at a $p$ value $<0.05$. The analyses were performed using SPSS statistical software, version 20 (SPSS Inc.).

Institutional review board approval was not required, as patients were treated with approved diagnostic and therapeutic procedures according to generally accepted standards of care.

\section{Results}

There were 19 patients in the anterior group and 23 patients in the posterior group. A presurgical comparison showed that there was no statistical difference ( $p$ 0.05) between patients, who underwent anterior and posterior surgeries. Length of stay in hospital for patients, who underwent anterior surgery, was on average 1.7 days shorter than those who underwent posterior surgery ( 3.7 vs $5.4, p<0.05$ ).

In the anterior group (group A), corpectomies were performed in 14 patients at the $C-5$ level, and 5 patients C- 4 level. The followup period in this group was 1.2 years. The implantation of the expandable cages was performed without complications and the adjustment of the height could be performed in situ. There were no complications reported during surgery and no infections, dysphagia or migration of the expandable cage during follow-up.

In the posterior group, all laminoplasty and laminectomies and instrumentation were performed at multiple levels. Involving 2 levels in 1 case (C3-4), 3 levels in 6 cases (C3-5 in 4 cases, and C4-6 in 14 cases), and 4 levels in 2 cases (C4-7 in 1 case, and C1-4 in 1 case). The follow-up period in this group was 1.3 years.

Clinical evaluation revealed significant improvement of both groups following spinal cord decompression according to scores on the mJOA scale and Nurick $(p<0.05)$. The comparison between the anterior and posterior groups shows a difference statistical for the posterior approach. After the operations according to the Nurick and mJOA scale score $(p<0.05)$ No complications, deep venous 
Table 4

Functional outcomes at follow-up.

\begin{tabular}{llll}
\hline Variable & Anterior (19) & Posterior (23) & $p$ value \\
\hline mJOA & & & \\
Pre & 6.89 & 6.43 & $p>0.05$ \\
Post & 15.52 & 17.13 & $p<0.05$ \\
Value $p$. pre/Fol. & $p<0.05$ & $p<0.05$ & \\
Nurick & & & $p>0.05$ \\
Pre & 3.73 & 3.82 & $p<0.05$ \\
Post & 0.73 & 0.30 & \\
Value $p$. pre/Fol. & $p<0.05$ & $p<0.05$ & \\
\hline
\end{tabular}

Fol., follow-up. Values are presented in percentage.

thrombosis, surgical site infection or Implant loosening, were reported in any patient during follow-up (Table 4). Patients in the posterior group showed a better improvement in JOA scores compared with the anterior group at the early follow-up at 1.4 years.

\section{Discussion}

The ideal treatment in CSM is still a matter of discussion, offering various alternatives, being the anterior, posterior or combined approaches. Anterior decompression is indicated in patients with one or two segments affected, and it has been observed that it offers better correction of kyphotic deformities and recovering sagittal balance. When the patient has 3 or more segments affected there has been reports of higher no-union rates, for which posterior approach is preferred. Posterior decompression is indicated, when three or more segments are affected, or when the posterior longitudinal ligament is ossified, in these cases the recommendation is to realize laminectomy, it should always be accompanied by instrumentation and fusion because of the high risk of kyphosis after laminectomy is performed. Both techniques offer similar functional results. Reports of axial cervical pain after posterior decompression have been made. The affection of more than 3 segments with additional kyphosis is a clear indication for combined approach (Table 5). . $^{3,-13,17,18}$

Clinical outcome can be achieved using both approaches, which is also reflected in the present study. Anterior pathologies that involve only 1 or 2 vertebral body levels usually proceed using an anterior approach, while in cases of more than 2 levels the posterior approach appears to be more suitable due to swallowing difficulty and construct failure. However, in cases involving multilevel disease with kyphosis, where the spinal cord is stretched over anterior osteophytes, a combined approach using anterior release and reconstruction of lordosis as well as posterior decompression with instrumentation may be suitable. ${ }^{13,14,17}$

An adequate decompression of neurological elements offers suitable functional results in both approaches, ${ }^{13,14,17,18}$ which was observed in the present study. In the anterior decompression group, corpectomy was preferred adding expandable cage and anterior cervical plating, although autologous grafting has demonstrated similar results compared with the expandable cage, the use of the expandable cage was preferred by the surgeon in these cases. The most affected segments were C-5/C-6; in those who had posterior osteophytes and in some cases vertebral disk herniation in both segments. In cases, where the disk herniation was the cause of compression, the anterior approach with discoidectomy, and disc prosthesis was recommended. ${ }^{15,16,18}$ Within patients with posterior decompression, all had at least 3 segments affected. Laminectomy with instrumentation and fusion was the choice of treatment. In the cases where laminoplasty was chosen, these lacked significant kyphosis, spinal canal was $>10 \mathrm{~mm}$ and no comorbidities were found (diabetes, arterial hypertension, osteoporisis, etc.). Even though patients with posterior approach presented better outcomes compared with the anterior approach, in mJOA such as Nurick scales. Both groups were analyzed independently and showed similar results in both scales. Independently if the approach was made anterior or posterior, if a decompression is made, patients present with important clinical improvement. Treatment has to be individualized with every patient, taking to account the imagery, number of segments affected, according to the radiological characteristics of the lesion, cervical sagittal balance and the surgeons surgical knowledge. ${ }^{18}$ One year follow-up is a short term being that implant failure and migration of cervical expandable cage may occur in the anterior approach group and concerning the posterior group, loosening of the screws, reappearance of myelopathy symptoms by the presence of fibrosis as well as closure of the opening in laminoplasty cases that buttress plates were not used. There are studies that demonstrate than in a short term follow up posterior decompression has better results compared with an anterior approach, but in a longer follow up no differences were found. ${ }^{17,20,21}$

Our study had several limitations. The patients were not randomized to the surgical procedure they underwent. The type of surgical procedure to be performed was surgeon dependent. The

Table 5

Approaches for cervical spondylotic myelopathy.

\begin{tabular}{|c|c|c|c|}
\hline & Anterior & Posterior & Combined \\
\hline Role of the extent of the disease & $\begin{array}{l}\text { One or two segments involved, up to } 3 .^{3} \\
\text { Kyphosis can diminish and in some cases } \\
\text { be corrected in its whole. } .^{8,9}\end{array}$ & $\begin{array}{l}\text { Three or more segments without } \\
\text { kyphosis. }{ }^{3,8} \\
\text { Severe osteoporosis and stenosis } \\
\text { of multiple segments. }\end{array}$ & $\begin{array}{l}\text { At least three segments with } \\
\text { additional kyphosis. }^{3} \\
\text { Decompression of three or more } \\
\text { segments, specially with low } \\
\text { bone quality. } \\
\text { Swan neck deformity. }^{9}\end{array}$ \\
\hline Role of the spinal canal diameter & & $\begin{array}{l}\text { Development of sever stenosis. }{ }^{3,8,9} \\
\text { Canal diameter }<11 \mathrm{~mm} \text { and } \\
\text { involvement of multiple. }\end{array}$ & \\
\hline $\begin{array}{l}\text { Role of the localization } \\
\text { of the deformity }\end{array}$ & $\begin{array}{l}\text { A good visualization of the anomaly found } \\
\text { on the anterior section, spares the effort } \\
\text { to go around the spinal cord. } \\
\text { One or two segments with a space-occupying } \\
\text { lesion as osteophytes or disc tissue. } .^{3,9} \\
\text { Herniated posterior longitudinal ligament. }^{9}\end{array}$ & $\begin{array}{l}\text { Buckling of the ligamentum flavum or } \\
\text { vertebral lamina ladder deformity } \\
\text { in patients with hyperlordosis. }\end{array}$ & \\
\hline Role of the preoperative neck pain & $\begin{array}{l}\text { Disruption of posterior paraspinal by a } \\
\text { posterior approach can aggravate the pain. }{ }^{3,8}\end{array}$ & & \\
\hline Role of prior surgery & Postoperative of laminectomy. ${ }^{3,9}$ & Postoperative of anterior approach. ${ }^{3}$ & \\
\hline
\end{tabular}


number of levels compared was different as anterior surgery involved slightly fewer levels compared with posterior surgery.

\section{Conclusions}

Our results demonstrated that patients with multilevel cervical myelopathy when treated with posterior approach do well and compare favorably with patients treated with an anterior approach at the midterm follow-up of 1.4 years. The main objective of the CSM treatment is the decompression of neurological structures. Although both approaches, offer adequate functional results; it has been proved that in patients with CSM, the posterior decompression offers better results compared with the anterior approach at $1.4 \mathrm{~s}$ year follow-up, both in mJAO as in Nurick scales. We believe that in the posterior approach decompression better functional results are obtained by the extensive spinal cord decompression multilevel, unlike the anterior approach, where decompression was performed in only 1 or 2 levels. The follow-up period is short, so we believe that patients with anterior decompression show a clinical improvement at 2 years, as reported in other studies. ${ }^{19-21}$

\section{Conflict of interest}

The authors, their immediate families, and any research foundations with which they are affiliated have not received any financial payments or other benefits from any commercial entity related to the subject of this article.

\section{References}

1. Brain WR, Northfield D, Wilkinson M. The neurological manifestations of cervical spondylosis. Brain. 1952;75(June (2)):187-225.

2. Toledano M, Bartleson JD. Cervical spondylotic myelopathy. Neurol Clin. 2013:31(February (1)):287-305.

3. Rao RD, Currier BL, Albert TJ, et al. Degenerative cervical spondylosis: clinical syndromes, pathogenesis, and management. J Bone Jt Surg Am. 2007;89(June (6)):1360-1378.

4. Mummaneni PV, Kaiser MG, Matz PG, et al. Cervical surgical techniques for the treatment of cervical spondylotic myelopathy. J Neurosurg Spine. 2009;11(August (2)):130-141.
5. Cunningham MR, Hershman S, Bendo J. Systematic review of cohort studies comparing surgical treatments for cervical spondylotic myelopathy. Spine (Phila Pa 1976). 2010;35(March (5)):537-543.

6. Kato S, Oshima Y, Oka H, et al. Comparison of the Japanese Orthopaedic Association (JOA) Score and Modified JOA (mJOA) Score for the assessment of cervical myelopathy: a multicenter observational study. PLOS ONE. 2015;10(4):e0123022.

7. Koning SA, Spetzger U. Surgical management of cervical spondylotic myelopathyindications for anterior, posterior or combined procedures for decompression and stabilisation. Acta Neurochir (Wien). 2014:156(2):253-258.

8. Meyer F, Wolfgang B, Claudius C. Degenerative cervical spinal stenosis. Deutsch Arztebl Int. 2008;105(20):366-372.

9. Sah S, Wang L, Dahan M, Acharya P, Dwivedi R. Surgical management of cervical spondylotic myelopathy. J Nepal Med Assoc. 2012;52(188):172-177.

10. Gok B, McLoughlin GS, Sciubba DM, et al. Surgical management of cervical spondylotic myelopathy with laminectomy and instrumented fusion. Neurol Res. 2009;31(December (10)):1097-1101.

11. Siemionow KB, Neckrysh S. Anterior approach for complex cervical spondylotic mylopathy. Orthop Clin N Am. 2012;43(January (1)):41-52.

12. Konya D, Ozgen S, Gercek A, Pamir MN. Outcomes for combined anterior and posterior surgical approaches for patients with multisegmental cervical spondylotic myelopathy. J Clin Neurosci. 2009;16(March (3)):404-409.

13. Fehlings MG, Barry S, Kopjar B, et al. Anterior versus posterior surgical approaches to treat cervical spondylotic myelopathy: outcomes of the prospective multicenter AOSpine North America CSM study in 264 patients. Spine (Phila Pa 1976). 2013;38(December (26)):2247-2252.

14. Sun Y, Li L, Zhao J, Gu R. Comparison between anterior approaches and posterior approaches for the treatment of multilevel cervical spondylotic myelopathy: meta-analysis. Clin Neurol Neurosurg. 2015;134(July):28-36.

15. Quinn JC, Kiely PD, Lebl DR, Hughes AP. Anterior surgical treatment of cervical spondylotic myelopathy: review article. HSS J. 2015;11(February (1)):15-25.

16. Liu X, Min S, Zhang H, Zhou Z, Wang H, Jin A. Anterior corpectomy versus posterior laminoplasty for multilevel cervical myelopathy: a systematic review and metaanalysis. Eur Spine J. 2014;23(February (2)):362-372.

17. Zhu B, Xu Y, Liu X, Liu Z, Dang G. Anterior approach versus posterior approach for the treatment of multilevel cervicalspondylotic myelopathy: a systemic review and meta-analysis. Eur Spine J. 2013;22(July (7)):1583-1593.

18. Cabraja M, Abbushi A, Koeppen D, Kroppenstedt S, Woiciechowsky C. Comparison between anterior and posterior decompression with instrumentation for cervical spondylotic myelopathy: sagittal alignment and clinical outcome. Neurosurg Focus 2010;28(March (3)):E15.

19. Edwards II CC, Heller JG, Murakami H. Corpectomy versus laminoplasty for multilevel cervical myelopathy: an independent matched cohort analysis. Spine. 2002;27:1168-1175.

20. Gray MJ, Biyani A, Smith A. A retrospective analysis of patient perceived outcomes in patients 55 years and older undergoing anterior cervical discectomy and fusion. J Spinal Disord Tech. 2010;23:157-161.

21. Seng C, Tow BP, Siddiqui MA, et al. Surgically treated cervical myelopathy: a functional outcome comparison study between multilevel anterior cervical decompression fusion with instrumentation and posterior laminoplasty. Spine J. 2013;13(7):723-731 